\title{
Social Factors Associated With Psychological Distress and Health Problems Among Elderly Members of a Disaster-Affected Population: Subgroup Analysis of a 1 -Year Post-disaster Survey in Ishinomaki Area, Japan
}

\author{
Mariko Inoue, PhD; Kazue Yamaoka, PhD
}

\section{ABSTRACT}

Objective: We aimed to investigate the influence of social factors, especially social support, on psychological distress and the prevalence of health problems (HPs) among victims living in their homes 14 to 21 months after the Great East Japan Earthquake and tsunami.

Methods: A subgroup analysis was performed for elderly participants of a cross-sectional household survey in Ishinomaki area, Japan. The prevalence of psychological HPs was assessed by using a psychological distress questionnaire (K6) and by recording the number of subjective HPs. Perceived social support was assessed in 3 dimensions: informational, emotional, and instrumental support. Univariate and multivariate logistic regression models were used to examine the association between social factors and psychological health.

Results: An elderly subgroup with 879 participants was used for analyses. Psychological distress ( $\mathrm{K} 6$ score $\geq 9$ ) was observed in $6.8 \%$ of the participants aged 65 to 74 years and in $8.0 \%$ of those aged $\geq 75$ years. Receiving a long-term care service was associated with having HPs, and discontinuation of attendance at a hospital as an outpatient was associated with psychological distress. Receiving emotional support was associated with lower psychological distress and not having HPs.

Conclusions: Emotional support was found to be an important factor for promoting health among elderly disaster victims. (Disaster Med Public Health Preparedness. 2017;11:64-71)

Key Words: Great East Japan Earthquake, disaster victims, social support, psychological health problems, elderly care

$\mathrm{F}$ ollowing a disaster, it can take a long time for people to return to their usual daily life. The victims of disasters suffer from physical health problems and psychological distress because of the influence of the disaster on their lives and the loss of their family, friends, property, belongings, and jobs. ${ }^{1}$

Forms of stress-related psychological distress, such as sleep disturbances, ${ }^{2}$ post-traumatic stress disorders, ${ }^{3}$ anxiety disorders, depression, ${ }^{4}$ and suicidal ideation, ${ }^{5}$ are common psychological responses among victims of disasters. Suicide is the most severe outcome of mental health problems after a disaster. ${ }^{6}$ Psychological recovery after a disaster often takes a long time, ${ }^{7}$ and assessing the survivors' risk of mental disorders to provide them with the appropriate care is one of the most important issues for public health care, even many years after the disaster. $^{8}$ Therefore, during the medium-term recovery period, the mental and psychological health of survivors, in relation to their social support and social ties, is an issue that requires greater attention, ${ }^{9,10}$ alongside existing governmental and nongovernmental assistance.
It is widely recognized that the elderly are among the most vulnerable populations both at the time of a disaster and during the recovery period. The majority $(66 \%)$ of those who died as a result of the Great East Japan Earthquake (GEJE) and tsunami were elderly people. The number of elderly victims who passed away within 2 years after the GEJE due to earthquakerelated causes was reported as $2688(89.1 \%$ of all deaths among the elderly during this period) in March 2013. ${ }^{11}$ At present, the volume and structure of the global population are undergoing dramatic changes. The size of the world's population is rapidly growing and population aging is occurring, especially in the Asia Pacific region. The Asia Pacific region is the most disaster-prone region of the world. This region has been struck by 1625 disasters during the last 10 years amounting to over $40 \%$ of the global total. ${ }^{12}$ Thus, determining the needs of the aged population to help build communities that are resilient to disaster is a crucial goal in the Asia Pacific region. Despite the importance of this area of research, the number of studies specifically focused on the elder demographic 
of disaster-affected populations has been limited. Most studies related to disaster areas have focused on the physical state of health including physical inactivity ${ }^{13,14}$ and stroke. ${ }^{15}$ Some studies have found that elderly people are at risk of experiencing depressive reactions, ${ }^{16}$ higher psychological distress associated with increased rate of hospital admissions due to pneumonia and chronic respiratory diseases after the GEJE,$^{17}$ and worsening depressive symptoms associated with the disturbance of psychiatric care. ${ }^{18}$

Social support is a function of social networks: it is accessible to individuals via other individuals, groups, family, and communities. ${ }^{19}$ Social support can be defined by 4 components: emotional, instrumental, informational, and appraisal. ${ }^{20,21}$ A number of studies have suggested that social support influences the health of individuals. ${ }^{22}$ Several beneficial effects of social support, including protection against psychological stress, ${ }^{23}$ encouraging healthy behaviors $^{24-26}$ and coping ability, ${ }^{27,28}$ and promoting cooperation with medical regimens, ${ }^{29}$ have been supported by previous studies. However, the association between social support and health problems among the elderly has not been studied in detail in a disaster-affected population. To our knowledge, the subject of whether functional aspects of social support particularly play a role in a disaster-affected elderly population has not been investigated. Therefore, we decided to focus on investigating the potential association of social factors and social support with the existence of psychological distress and health problems among the elderly after the GEJE disaster.

Ishinomaki in Miyagi prefecture was the area most damaged by the tsunami caused by the GEJE along the Pacific coast in the Tohoku region. We previously investigated the association between social factors and sleep difficulties among survivors of the 2011 GEJE and tsunami in the Ishinomaki area ${ }^{30}$ In that study, the subjects consisted of 4176 disasteraffected victims who chose to continue living in their damaged homes rather than move to temporary shelters or housing in the 6 to 12 months after the disaster.

The aims of the current study were to identify psychosocial and health problems among survivors living at home by using data obtained 14 to 21 months after the GEJE and tsunami and to investigate the role of social support or social factors on influencing the existence of psychosocial and health symptoms.

\section{METHODS}

This study was a subgroup analysis of the second-phase faceto-face survey conducted by the Health and Life Revival Council in Ishinomaki District (RCI) between May and December 2012 (14 to 21 months after the disaster) after the GEJE and tsunami in March 2011. The details of RCI's activities and the overall survey methodology have been described elsewhere. ${ }^{30,31}$
The survey consisted of 3 parts. The first was conducted in a face-to-face manner by a representative of the household, and it included questions related to household demographics and the social background of the household members. The second part involved obtaining responses from all household members who were at home at the time of the visit; it mainly included questions related to interviewee lifestyle. The third part was in the form of a questionnaire given to each adult household member and was returned to the RCI by post upon completion. The items on this third questionnaire mainly related to the physical and psychosocial health condition of the respondents (including prolonged sleep difficulties). In this survey, we visited 13,137 households in the areas of Ishinomaki, which was one of the cities most severely damaged by the disaster. The surveyors asked the household member or members who were home at the time to participate in the survey and also distributed a questionnaire for each of the other household members to return after completion. We were able to contact people in 8021 households, individuals from 4032 households (11,430 eligible subjects) responded to the survey, and 2593 individuals from 1709 households responded to the third step of the survey. Of those 2593 subjects, 879 elderly individuals were used for this subgroup analysis. The questionnaire assessed each respondent's psychological health status and social factors, including their access to 3 dimension of social supports, the family structure of the household, the severity of damage to the house, and their medical care, current lifestyle, and so on. All of the participants gave written consent to participate. Ethical approval for this study was obtained from the Institutional Review Board of Teikyo University (reference number: 12-079).

\section{Measurements \\ Health Problems}

The number of health problems affecting each respondent was evaluated by the question, "Do you have any subjective symptoms that have lasted for longer than 1 month that may affect your daily life?" The number of positive responses was counted among the 18 possible responses of "sleep difficulties," "headache," "dizziness," "throbbing," "stomachache," "loss of appetite," "overeating," "asthma," "sore throat," "phlegm and cough," "blurred vision," "dermatitis," "allergy," "stiff shoulders," "backache," "knee pain," "over-sleeping," and "others." As our final outcome, each person who selected at least 1 of these 18 responses was categorized as "having health problems."

\section{Kessler Psychological Distress Scale (K6)}

To assess psychological health, we used a validated Japanese version of the Kessler Psychological Distress Scale (K6). ${ }^{32}$ The K6 measures moderate mental distress based on mental health treatment need and utilization. ${ }^{33}$ The $\mathrm{K} 6$ is a 6-question scale widely used to screen those with psychological distress in community epidemiological studies. The items included questions such as, "During the last 30 days, about how often did you feel so depressed that nothing could 
cheer you up?" Participants rated each question on 4-point Likert scale from 0 (not at all) to 4 (always). The total score ranged from 0 to 24, with a higher score indicating a greater risk of psychological distress. When screening for nonspecific psychological distress, including mood or anxiety disorders, a score of 9 was used as a cutoff. When screening for those with serious mental illnesses, Kessler and colleagues demonstrated that a score of 13 is an optimal cutoff point internationally.

\section{Demographics and Social Factors}

The demographic information collected about participants included the following items: age, sex, the number of household members, the source of the household's income, the local government's recognition of the severity of damage to the home, and changes in family structure or income due to the disaster. Those were the same as or similar to the parameters used in our previous study, thereby allowing a comparison of the results. Data about the following were obtained as household sociodemographic information. The number of household members was divided into 3 categories and classified into 2 groups: (1) 1 member, (2) more than 1 member. The source of income was divided into the following 2 categories: (1) only salary or pension and salary, (2) only pension, public livelihood assistance, unemployment allowance, no regular income, or other. The severity of damage to the home was rated on a 5-point scale: (0) none, (1) partially damaged, (2) half-destroyed, (3) largely destroyed, and (4) totally destroyed. A change in family structure was defined as any change in the number of household members due to the disaster, eg, the death or relocation of family members. Changes in family structure or income as a result of the disaster were responded to dichotomously. Social support was divided into its 3 dimensions: emotional, instrumental, and informational support. Owing to limited interview time and also because of the relative lack of research and evidence on appraisal support for health, we did not assess dimension of appraisal support in this study as described in the former study. ${ }^{27}$ These items were used after being classified as shown in Table 1 .

\section{Statistical Analysis}

The participants' characteristics as related to demographics, social support, and other social factors and their prevalence of psychological health problems were summarized with descriptive statistics. We also compared our results between the elderly population aged over 65 years and the younger population aged less than 64 years by chi-square test. Logistic regression analyses were used to examine the statistical associations between each outcome variable (health problems and K6 scores) and the explanatory variables related to demographics and social factors. Multivariate-adjusted odds ratios (ORs) with 95\% confidence intervals (95\% CIs) were obtained by a stepwise selection method (inclusion and exclusion criteria 0.20 ). All analyses were performed by using SAS software (version 9.4; SAS Institute, Cary, NC, USA). All tests were 2-sided, with a significance level of $5 \%$.

\section{TABLE 1}

\section{Characteristics of Respondents in the Elderly Age Group} ( $\geq 65$ Years of Age) ${ }^{\mathrm{a}}$

All

Sex

Male

Female

Missing

Live alone (yes)

Source of household income

Salary/pension and salary Other ${ }^{\mathrm{b}}$

Severity of house damage

Totally/largely/half destroyed

Partially destroyed/none

Missing/unknown

Frequency of going outdoors

$\geq 5$ times per week

3-4 times per week

$<2$ times per week

Missing

Change in family structure due to disaster Yes

No

Missing

Change in income due to disaster Yes

No

Missing

Having no social support at all

Having a supportive person

Somewhat

No one to depend on

Missing

Having emotional social support

Yes

No

Missing

Having instrumental social support Yes

No

Missing

Having informational social support

Yes

No

Missing

Attendance of a hospital as an outpatient

Not attended a hospital (including nonresponse)

Continued to attend

Discontinued

Receiving long-term care services

Not receiving (including nonresponse)

Support level

Care level

Respondents Respondents

Aged 65-74y Aged $\geq 75 y$

No. $\%$ No. $\%$

$\begin{array}{llll}541 & 100.0 & 338 & 100.0\end{array}$

$\begin{array}{llll}223 & 41.2 & 154 & 45.6\end{array}$

$\begin{array}{llll}317 & 58.6 & 183 & 54.1\end{array}$

$\begin{array}{llll}1 & 0.2 & 1 & 0.3\end{array}$

$\begin{array}{llll}50 & 9.2 & 64 & 18.9\end{array}$

$\begin{array}{llll}308 & 56.9 & 156 & 46.2\end{array}$

$\begin{array}{llll}233 & 43.1 & 182 & 53.9\end{array}$

$\begin{array}{llll}409 & 75.6 & 248 & 73.4\end{array}$

$\begin{array}{llll}100 & 18.5 & 67 & 19.8\end{array}$

$\begin{array}{llll}32 & 5.9 & 23 & 6.8\end{array}$

121

22.4114

33.7

$\begin{array}{llll}166 & 30.7 & 87 & 25.7\end{array}$

$\begin{array}{llll}251 & 46.4 & 135 & 39.9\end{array}$

$\begin{array}{llll}3 & 0.6 & 2 & 0.6\end{array}$

$\begin{array}{llll}81 & 15.0 & 57 & 16.9\end{array}$

$\begin{array}{llll}459 & 84.8 & 280 & 82.8\end{array}$

$\begin{array}{llll}1 & 0.2 & 1 & 0.3\end{array}$

$\begin{array}{llll}178 & 32.9 & 84 & 24.9\end{array}$

$\begin{array}{llll}360 & 66.5 & 254 & 75.2\end{array}$

$\begin{array}{llll}3 & 0.6 & 0 & 0.0\end{array}$

$\begin{array}{llll}184 & 34.0 & 138 & 40.8\end{array}$

$\begin{array}{llll}319 & 59.0 & 173 & 51.2\end{array}$

$\begin{array}{llll}14 & 2.6 & 8 & 2.4\end{array}$

$\begin{array}{llll}24 & 4.4 & 19 & 5.6\end{array}$

$\begin{array}{llll}443 & 81.9 & 277 & 82.0\end{array}$

$\begin{array}{llll}74 & 13.7 & 42 & 12.4\end{array}$

$\begin{array}{llll}24 & 4.4 & 19 & 5.6\end{array}$

$\begin{array}{llll}33 & 6.1 & 52 & 15.4\end{array}$

$\begin{array}{llll}484 & 89.5 & 267 & 79.0\end{array}$

$\begin{array}{llrr}24 & 4.4 & 19 & 5.6\end{array}$

$\begin{array}{llll}199 & 36.8 & 135 & 39.9\end{array}$

$\begin{array}{llll}318 & 58.8 & 184 & 54.4\end{array}$

$\begin{array}{llll}24 & 4.4 & 19 & 5.6\end{array}$

$435 \quad 80.4 \quad 154 \quad 45.6$

$\begin{array}{llll}105 & 19.4 & 181 & 53.6\end{array}$

$\begin{array}{llrr}1 & 0.2 & 3 & 0.9\end{array}$

$\begin{array}{llll}538 & 99.4 & 314 & 92.9\end{array}$

$\begin{array}{llll}2 & 0.4 & 21 & 6.2\end{array}$

${ }^{a}$ No. is the number of respondents, including nonresponse.

${ }^{\mathrm{b}}$ Pension, public livelihood assistance, unemployment allowance, no regular income, and other. 


\section{RESULTS}

An elderly subgroup with 879 participants was used for the analyses. The characteristics of the elderly respondents are shown in Table 1. The proportions of individuals having psychological distress among the elderly survivors is shown in Table 2. Psychological distress (K6 score $\geq 9$ ) was observed in $6.8 \%$ of the survey respondents aged 65 to 74 years and in $8.0 \%$ of those aged $\geq 75$ years. The proportion of the population who were classified as being at risk of committing suicide was higher in those aged $\geq 75$ years than in those aged 65 to 74 years, although the difference was not statistically significant. The proportions of elderly survey respondents having any health problems were $36.7 \%$ and $32.7 \%$, and those having psychological distress were $31.7 \%$ and $29.0 \%$, respectively, among those aged $\geq 75$ and 65 to 74 years.

The results of the multivariate model are shown in Table 3. The 3 dimensions of social support (emotional, instrumental, and informational support) were used as explanatory variables rather than as the broader indicator related to social support. Having emotional social support was associated with psychological distress (OR: 0.49; 95\% CI: 0.26-0.93) and a lower prevalence of health problems (OR: 0.63; 95\% CI: 0.41-0.98). Instrumental and informational social support did not significantly influence psychological distress and the existence of health problems. In addition, we found that

\section{TABLE 2}

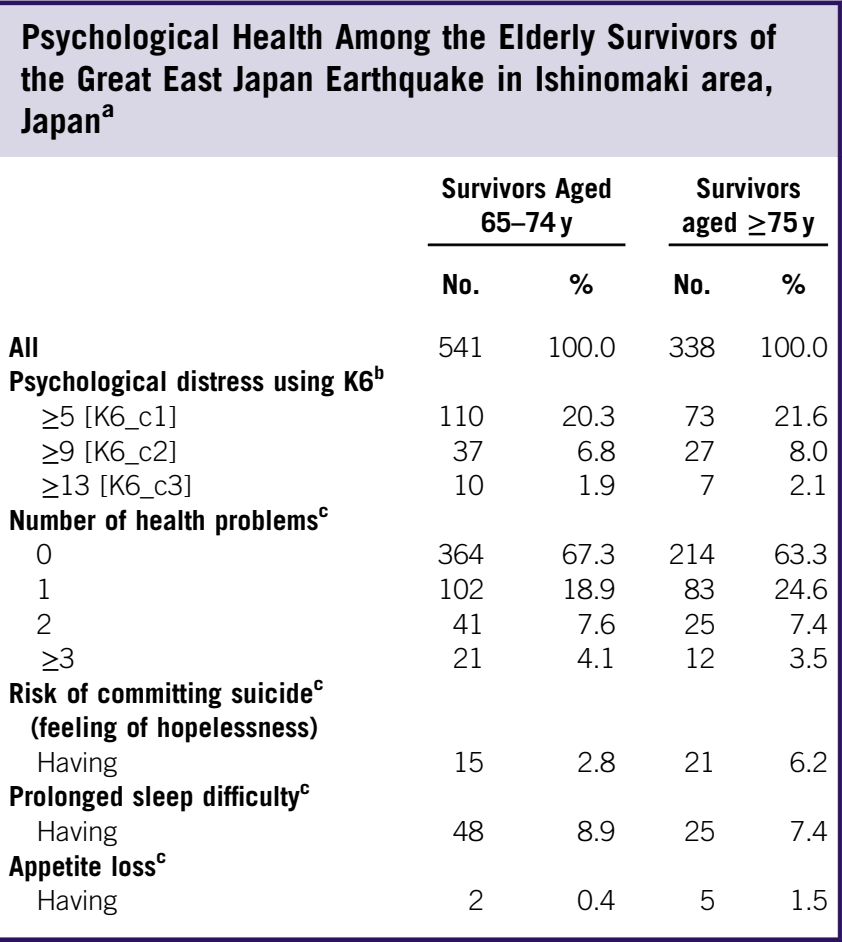

${ }^{\mathrm{a} N o}$. is the number of respondents. Prolonged sleep difficulties were defined as sleep difficulties that lasted for more than 1 month. K6, Kessler Psychological Distress Scale.

${ }^{\mathrm{b}}$ Number of cases missing data: $65-74$ years $=5 ; \geq 75$ years $=4$.

${ }^{\mathrm{c}}$ Number of cases missing data: $65-74$ years $=12 ; \geq 75$ years $=4$. receiving a long-term care service was associated with having health problems (OR: 3.05; 95\% CI: 1.20-7.76), and the discontinuation of attendance at a hospital as an outpatient was associated with increased psychological distress (OR: 48.54; 95\% CI: 4.15-567.11). The nonmodifiable or hardly modifiable consequences caused directly by the disaster, such as the severity of damage to respondents' homes and changes in their family structure or income due to the disaster, were not significantly associated with prolonged psychosocial distress and the existence of health problems.

\section{DISCUSSION}

We examined whether social factors and the 3 dimensions of social support were associated with psychological distress and health problems among elderly victims who were living at home 14 to 21 months after the GEJE and tsunami. A lack of social support was more strongly associated with psychological distress and having health problems than were nonmodifiable or hardly modifiable consequences caused directly by the disaster such as the severity of damage to respondents' homes and changes in their family structure and income among the elderly. Among the 3 dimensions of social support, a lack of emotional support was associated with a higher prevalence of health problems and psychological distress.

\section{Psychosocial Distress}

Psychosocial distress was higher in the elderly population in this study than in younger respondents aged $<65$ years. We also found that the percentage of individuals classified as having suicidal intentions was higher among the elderly respondents than in the younger respondents. The most aged population in our study might feel a sense of hopelessness. However, the Comprehensive Survey of Living Conditions in 2013 reported that the percentage of elderly people, categorized as exhibiting psychosocial distress $(\mathrm{K} 6 \geq 10)$ in the same age group ( $\geq 75$ years) was higher than the national average for all age groups. Another previous Japanese study conducted after a different earthquake also showed a similar result soon (16-30 weeks) after the earthquake ${ }^{34}$ and in the medium-term period (45-80 weeks) after the earthquake. ${ }^{35}$ To gain a full understanding of the psychological distress experienced by disaster-affected victims, we need to carefully monitor disaster victims over a long period of time.

Our results showed that living alone was not significantly associated with psychological distress. The elderly population might not feel isolation regardless of whether they live together with others. Intervention from friends, neighbors, relatives living elsewhere, or even volunteers could prevent the elderly from feeling psychological distress. A previous study showed that having a social network helps to prevent mental health problems. ${ }^{36}$ The elderly need continuous follow-up to prevent them from disaster-related death due to psychological distress. $^{37}$ 


\begin{tabular}{|c|c|c|c|c|c|c|}
\hline & \multicolumn{3}{|c|}{ K6 } & \multicolumn{3}{|c|}{ Health problems } \\
\hline & Odds Ratio & $95 \% \mathrm{Cl}$ & $P$ Value & Odds Ratio & $95 \% \mathrm{Cl}$ & $P$ Value \\
\hline \multicolumn{7}{|l|}{ Age } \\
\hline $\begin{array}{l}\geq 75 y \\
65-74 y\end{array}$ & $\begin{array}{l}0.72 \\
1.00\end{array}$ & $0.40-1.31$ & 0.286 & $\begin{array}{l}1.09 \\
1.00\end{array}$ & $0.77-1.53$ & 0.624 \\
\hline \multicolumn{7}{|l|}{ Lives alone } \\
\hline Not alone & 1.00 & & & $-^{a}$ & & \\
\hline Alone & 2.02 & $0.94-4.33$ & 0.071 & & & \\
\hline \multicolumn{7}{|l|}{ Source of household income } \\
\hline Salary/pension and salary & 1.00 & & & 1.00 & & \\
\hline Other & 0.64 & $0.36-1.16$ & 0.142 & 0.76 & $0.55-1.05$ & 0.092 \\
\hline \multicolumn{7}{|l|}{ Damage due to disaster } \\
\hline Yes & 1.94 & $0.88-4.26$ & 0.100 & & & \\
\hline No & 1.00 & & & $-^{a}$ & & \\
\hline \multicolumn{7}{|l|}{ Frequency of going outdoors } \\
\hline$\geq 5$ times per week & 1.00 & & & 1.00 & & \\
\hline 3-4 times per week & 0.54 & $0.28-1.04$ & 0.773 & 0.78 & $0.52-1.17$ & 0.845 \\
\hline$<2$ times per week & 0.35 & $0.18-0.66$ & 0.011 & 0.56 & $0.38-0.82$ & 0.005 \\
\hline \multicolumn{7}{|l|}{ Having emotional social support } \\
\hline Yes & 0.49 & $0.26-0.93$ & 0.029 & 0.63 & $0.41-0.98$ & 0.038 \\
\hline No & 1.00 & & & 1.00 & & \\
\hline \multicolumn{7}{|c|}{ Attendance of a hospital as an outpatient } \\
\hline Did not attend a hospital ${ }^{b}$ & 1.00 & & & 1.00 & & \\
\hline Continued to attend & 1.12 & $0.61-2.06$ & 0.709 & 1.24 & $0.87-1.78$ & 0.231 \\
\hline Discontinued & 48.54 & 4.15-567.11 & 0.002 & 6.61 & $0.65-66.90$ & 0.131 \\
\hline \multicolumn{7}{|c|}{ Receiving long-term care services } \\
\hline Not receiving ${ }^{\mathrm{b}}$ & $-^{a}$ & & & 1.00 & & \\
\hline Support level + care level & & & & 3.05 & $1.20-7.76$ & 0.019 \\
\hline
\end{tabular}

${ }^{a}$ Variables not selected by the stepwise selection method.

bIncluding nonresponse.

\section{Health Problems}

Health problems were more likely to be present among the elderly population. One dimension of social support, having emotional support, was associated with a lower prevalence of health problems. Elderly people who have persons who listen attentively to their concerns or follow them up closely might experience less concerns and have easier access to appropriate health services.

Receiving long-term care services was positively associated with having health problems, which is concordant with our expectations, because having poor health is a common reason for individuals to require long-term care. During the mediumterm recovery process, we need to pay attention to the recovery of usual daily life among the elderly population to provide them with easier access to health services and long-term care.

\section{Particular Concerns for the Elderly}

Our results suggest that the discontinuation of attendance at a hospital as an outpatient was associated with higher psychological distress, and receiving long-term care services was associated with having health problems. Access to health services and long-term care might reduce anxiety and the feeling of isolation in elderly individuals. Even 3 years after the GEJE, the prevalence of disability among the elderly population continued to be higher in the disaster-stricken areas. ${ }^{38}$ Our result supports that it is particularly important for the well-being of the elderly to keep their access to outpatient and long-term care services.

\section{Types of Social Support}

A lack of social support was more strongly associated with psychological distress and health problems than were the nonmodifiable or hardly modifiable consequences caused directly by the disaster. Among the 3 dimensions of social support, we found that emotional social support was associated with less psychosocial distress and a lower prevalence of health problems. In this study, among the elderly respondents, $13.7 \%$ of respondents aged $<75$ years and $12.4 \%$ of respondents aged $\geq 75$ years reported having emotional social support. Previous studies suggested that emotional support is the most important type of social support for health and wellbeing in the general population ${ }^{39-42}$ and in disaster-affected populations. ${ }^{43}$ 
The frequency of going outdoors, which might be a behavior connected with obtaining social support, was not associated with either psychosocial distress or the presence of health problems. The elderly people who went outdoors $<2$ times per week and 3 to 4 times per week had less psychological distress and fewer health problems than did those who went outdoors $\geq 5$ times per week. This result contradicted our hypothesis that a more active population might have a better health and psychological status. A possible explanation for this unexpected result might be that elderly people who leave their home less frequently have support from their family so that they do not often need to go outdoors themselves. Moreover, our results might be at risk of misclassification due to bias in the self-reporting by individuals about going outdoors. For example, respondents might not have consistently reported going out within a short distance of their homes. This result might also have been affected by the characteristics of the targeted population who were healthy enough to choose to remain in their half-destroyed or largely destroyed houses after the GEJE and tsunami disaster.

\section{Limitations}

To our knowledge, this is the first study to have investigated the relationship of the 3 dimensions of social support with health and psychological distress in a disaster-affected elderly population. However, there were several limitations to this study. First, we adopted a cross-sectional design, which limited the scope for making causal inferences based on the associations found. Moreover, the lack of detailed information about each surveyed health problem limited the resolution of our analysis of respondents' health, because we only analyzed the existence of health problems. Second, the survey participants were selected by a nonrandom method. Older and female people were more involved in this study, compared with the demographic characteristics of the residents living in Ishinomaki city at the time of our previous survey. ${ }^{44}$ Third, we only surveyed victims living at home after the GEJE and tsunami, not those living in temporary shelters, which might limit the generalizability of our findings. However, a study that investigated the effect of social support on mental health among victims of the GEJE and tsunami who were living in temporary shelters also reported that participants without social support had a higher risk of psychological distress. ${ }^{45,46}$ Therefore, our results might be concordant with those for victims living in different types of accommodation. Fourth, regarding the variables "change in family structure due to disaster" and "change in income due to disaster," we did not ask whether the number of household members or income increased or decreased due to the disaster. Considering the situation we assumed that most of the changes were decreases; however, future investigation should address this issue. Finally, missing data may have affected our results. However, because we obtained similar results in our supplementary analyses using the multiple imputation method, it appears that the effects of missing data on our findings were limited.
Despite these limitations, this study has important implications for future studies and local support during the mid-term period after disasters. Improving social support, especially emotional support, among elderly victims in disaster-affected communities appears to be an important step in promoting the health and recovery of such communities. In addition, receiving long-term care services after disasters prevents health problems. Possible support might be continuous health access for the elderly population in need of aid and emotional support from family, friends, or volunteers. In terms of implementation, we still need to enlist human resources who can contribute health services and emotional support after disasters and to put into practice the lessons from the study. Preparedness needs to take place in normal times.

In our study, we also focused on victims living at home at different time points after a natural disaster. Such populations often do not have reliable access to public services. The present investigation should thus provide important information that can be used in the design of strategies or interventions to reduce psychological distress and physical health complaints among a disaster-affected elderly population. Especially important is to give more emotional support for both age groups and to maintain long-term care services for the older age group to reduce their psychological distress.

\section{About the Authors}

Teikyo Ishinomaki Research Group, Teikyo University Graduate School of Public Health, Tokyo, Japan.

Correspondence and reprint requests to Mariko Inoue, PhD, Teikyo University Graduate School of Public Health, 2-11-1 Kaga, Itabashi, Tokyo, 173-8605, Japan (e-mail: inoue-ph@med.teikyo-u.ac.jp).

\section{Acknowledgments}

The authors thank Ms Ai Sonoda, Ms Miyuki Osaka, Mr Kohei Shiozawa, other members of RCI, and all the volunteers who made an enormous contribution to the data collection. We also received insightful comments and suggestions from the Teikyo Ishinomaki Research Group, the members of which are Prof Eiji Yano, Prof Kunio Hara, Dr Aya Ishiguro, Ms Shoko Matsumoto, Ms Yuriko Togita, and Ms Akie Midorikawa.

\section{Funding}

This study was supported by the Japan Public Health Society through a special grant for public health in the Great East Japan Earthquake in 2012.

Published online: November 15, 2016.

\section{REFERENCES}

1. Freedy JR, Simpson WM. Disaster-related physical and mental health: a role for the family physician. Am Fam Physician. 2007;75(6):841-846.

2. Wallen GR, Minniti CP, Krumlauf M, et al. Sleep disturbance, depression and pain in adults with sickle cell disease. BMC Psychiatry. 2014;14(1):207. http://dx.doi.org/10.1186/1471-244X-14-207.

3. Heid AR, Pruchno R, Cartwright FP, et al. Exposure to Hurricane Sandy, neighborhood collective efficacy, and post-traumatic stress symptoms in older adults. Aging Ment Health. 2016;25:1-9. http://dx.doi.org/10.1080/ 13607863.2016.1154016. 
4. Ozdemir O, Boysan M, Guzel Ozdemir P, et al. Relationships between posttraumatic stress disorder (PTSD), dissociation, quality of life, hopelessness, and suicidal ideation among earthquake survivors. Psychiatry Res. 2015;228(3):598-605. http://dx.doi.org/10.1016/j.psychres. 2015.05.045.

5. Rosellini AJ, Coffey SF, Tracy M, et al. A person-centered analysis of posttraumatic stress disorder symptoms following a natural disaster: predictors of latent class membership. J Anxiety Disord. 2014;28(1):16-24. http://dx.doi.org/10.1016/j.janxdis.2013.11.002.

6. Boscarino JA, Hoffman SN, Adams RE, et al. Mental health outcomes among vulnerable residents after Hurricane Sandy: implications for disaster research and planning. Am J Disaster Med. 2014;9(2):107-120. http://dx.doi.org/10.5055/ajdm.2014.0147.

7. Babson KA, Feldner MT. Temporal relations between sleep problems and both traumatic event exposure and PTSD: a critical review of the empirical literature. J Anxiety Disord. 2010;24(1):1-15. http://dx.doi.org/ 10.1016/j.janxdis.2009.08.002.

8. Harvey AG, Jones C, Schmidt DA. Sleep and posttraumatic stress disorder: a review. Clin Psychol Rev. 2003;23(3):377-407. http://dx.doi. org/10.1016/S0272-7358(03)00032-1.

9. Ford DE, Kamerow DB. Epidemiologic study of sleep disturbances and psychiatric disorders. An opportunity for prevention? JAMA. 1989;262(11):1479-1484. http://dx.doi.org/10.1001/jama.1989.0343011 0069030.

10. Godet-Cayré V, Pelletier-Fleury N, Le Vaillant M, et al. Insomnia and absenteeism at work. Who pays the cost? Sleep. 2006;29:179-184.

11. Cabinet Office, Government of Japan. Annual Report on the Aging Society: 2013, Korei Shakai Hakusho 2013 [in Japanese]. http://www8. cao.go.jp/kourei/whitepaper/w-2013/zenbun/25pdf_index.html. Accessed October 19, 2016.

12. United Nations Economic and Social Commission for Asia and the Pacific. Asia-Pacific Disaster Report 2015. http://www.unescap.org/sites/ default/files/Full\%20Report\%20\%20\%5BLow-Res\%5D.pdf. Accessed October 19, 2016.

13. Ishii T, Ochi S, Tsubokura M, et al. Physical performance deterioration of temporary housing residents after the Great East Japan Earthquake. Prev Med Rep. 2015;2:916-919. http://dx.doi.org/10.1016/j.pmedr.2015.10.009.

14. Yoshimura E, Ishikawa-Takata K, Murakami H, et al. Relationships between social factors and physical activity among elderly survivors of the Great East Japan earthquake: a cross-sectional study. BMC Geriatr. 2016;16(1):30. http://dx.doi.org/10.1186/s12877-016-0203-8.

15. Omama S, Yoshida Y, Ogasawara K, et al. Influence of the Great East Japan Earthquake and Tsunami 2011 on occurrence of cerebrovascular diseases in Iwate, Japan. Stroke. 2013;44(6):1518-1524. http://dx.doi.org/ 10.1161/STROKEAHA.111.000442.

16. Matsubara C, Murakami H, Imai K, et al. Prevalence and risk factors for depressive reaction among resident survivors after the tsunami following the Great East Japan Earthquake, March 11, 2011. PLoS One. 2014; 9(10):e109240. http://dx.doi.org/10.1371/journal.pone.0109240.

17. Yamanda S, Hanagama M, Kobayashi S, et al. The impact of the 2011 Great East Japan Earthquake on hospitalisation for respiratory disease in a rapidly aging society: a retrospective descriptive and cross-sectional study at the disaster base hospital in Ishinomaki. BMJ Open. 2013;3(1): e000865. http://dx.doi.org/10.1136/bmjopen-2012-000865.

18. Tsuboya T, Aida J, Hikichi $\mathrm{H}$, et al. Predictors of depressive symptoms following the Great East Japan earthquake: a prospective study. Soc Sci Med. 2016;161:47-54. http://dx.doi.org/10.1016/j.socscimed. 2016.05.026.

19. Lin N, Ensel WM, Simeone RS, et al. Social support, stressful life events, and illness: a model and an empirical test. J Health Soc Behav. 1979; 20(2):108-119. http://dx.doi.org/10.2307/2136433.

20. House JS. Work Stress and Social Support. Reading, MA: Addison-Wesley; 1981.

21. Langford CP, Bowsher J, Maloney JP, et al. Social support: a conceptual analysis. Adv Nurs. 1997;25(1):95-100. http://dx.doi.org/10.1046/j.13652648.1997.1997025095.x.
22. Reblin M, Uchino BN. Social and emotional support and its implication for health. Curr Opin Psychiatry. 2008;21(2):201-205. http://dx.doi.org/ 10.1097/YCO.0b013e3282f3ad89.

23. Cohen S. Psychosocial models of the role of social support in the etiology of physical disease. Health Psychol. 1988;7(3):269-297. http://dx.doi.org/ 10.1037/0278-6133.7.3.269.

24. Umberson D. Family status and health behaviors: social control as a dimension of social integration. J Health Soc Behav. 1987;28(3):306-319. http://dx.doi.org/10.2307/2136848.

25. Emmons KM, Barbeau EM, Gutheil C, et al. Social influences, social context, and health behaviors among working-class, multi-ethnic adults. Health Educ Behav. 2007;34(2):315-334. http://dx.doi.org/10.1177/ 1090198106288011 .

26. Chouinard MC, Robichaud-Ekstrand S. Predictive value of the transtheoretical model to smoking cessation in hospitalized patients with cardiovascular disease. Eur J Cardiovasc Prev Rehabil. 2007; 14(1):51-58. http://dx.doi.org/10.1097/HJR.0b013e328014027b.

27. McColl MA, Lei H, Skinner H. Structural relationships between social support and coping. Soc Sci Med. 1995;41(3):395-407. http://dx.doi.org/ 10.1016/0277-9536(94)00338-T.

28. Kim J, Han JY, Shaw B, et al. The roles of social support and coping strategies in predicting breast cancer patients' emotional well-being: testing mediation and moderation models. J Health Psychol. 2010;15 (4):543-552. http://dx.doi.org/10.1177/1359105309355338.

29. DiMatteo MR. Social support and patient adherence to medical treatment: a meta-analysis. Health Psychol. 2004;23(2):207-218. http:// dx.doi.org/10.1037/0278-6133.23.2.207.

30. Matsumoto S, Yamaoka K, Inoue M, et al. Social ties may play a critical role in mitigating sleep difficulties in disaster-affected communities: a cross-sectional study in the Ishinomaki area, Japan. Sleep. 2014;37(1): $137-145$.

31. Matsumoto S, Yamaoka K, Inoue M, et al. Implications for social support on prolonged sleep difficulties among a disaster-affected population: second report from a cross-sectional survey in Ishinomaki, Japan [published online June 18, 2015]. PLoS One. http://dx.doi.org/10.1371/ journal.pone. 0130615

32. Furukawa TA, Kawakami N, Saitoh M, et al. The performance of the Japanese version of the K6 and K10 in the World Mental Health Survey Japan. Int J Methods Psychiatr Res. 2008;17(3):152-158. http://dx. doi.org/10.1002/mpr.257.

33. Prochaska JJ, Sung HY, Max W, et al. Validity study of the K6 Scale as a measure of moderate mental distress based on mental health treatment need and utilization. Int J Methods Psychiatr Res. 2012;21(2):88-97. http:// dx.doi.org/10.1002/mpr.1349.

34. Suzuki Y, Tsutsumi A, Fukasawa M, et al. Prevalence of mental disorders and suicidal thoughts among community-dwelling elderly adults 3 years after the Niigata-Chuetsu earthquake. J Epidemiol. 2011;21(2):144-150. http://dx.doi.org/10.2188/jea.JE20100093.

35. Nakamura K, Kitamura K, Someya T. Psychological recovery 5 years after the 2004 Niigata-Chuetsu earthquake in Yamakoshi, Japan. J Epidemiol. 2014;24(2):125-131. http://dx.doi.org/10.2188/jea.JE20130097.

36. Yokoyama Y, Otsuka K, Kawakami N, et al. Mental health and related factors after the Great East Japan earthquake and tsunami. PLoS One. 2014;9(7):e102497. http://dx.doi.org/10.1371/journal.pone. 0102497.

37. Ichiseki H. Features of disaster-related deaths after the Great East Japan Earthquake. Lancet. 2013;381(9862):204. http://dx.doi.org/10.1016/ S0140-6736(13)60091-4.

38. Tomata Y, Suzuki Y, Kawado M, et al. Long-term impact of the 2011 Great East Japan Earthquake and tsunami on functional disability among older people: a 3-year longitudinal comparison of disability prevalence among Japanese municipalities. Soc Sci Med. 2015;147:296-299. http:// dx.doi.org/10.1016/j.socscimed.2015.11.016.

39. Semmer NK, Elfering A, Jacobshagen N, et al. The emotional meaning of instrumental social support. Int J Stress Manag. 2008;15(3):235-251. http://dx.doi.org/10.1037/1072-5245.15.3.235. 
40. Berkman LF. The role of social relations in health promotion. Psychosom Med. 1995;57(3):245-254. http://dx.doi.org/10.1097/00006842-19950500000006.

41. House JS, Umberson D, Landis KR. Structures and processes of social support. Annu Rev Sociol. 1988;14(1):293-318. http://dx.doi.org/10.1146/ annurev.so.14.080188.001453.

42. Stansfeld SA, Shipley MJ, Head J, et al. Work characteristics and personal social support as determinants of subjective well-being. PLoS One. 2013; 8(11):e81115. http://dx.doi.org/10.1371/journal.pone.0081115.

43. Shakespeare-Finch JE, Green J. Social support promotes psychological well-being following a natural disaster. National Emergency Response. 2013;26(3):14-17.
44. The Ishinomaki City statistical documentation based on Basic Resident Register (Chapter 3, Population) [in Japanese]. https://www.city.ishinomaki. lg.jp/cont/10102000/0040/3914/20130301161659.html. Accessed February 26, 2015.

45. Koyama S, Aida J, Kawachi I, et al. Social support improves mental health among the victims relocated to temporary housing following the Great East Japan Earthquake and Tsunami. Tohoku J Exp Med. 2014;234 (3):241-247. http://dx.doi.org/10.1620/tjem.234.241

46. Teramoto C, Matsunaga A, Nagata S. Cross-sectional study of social support and psychological distress among displaced earthquake survivors in Japan. Jpn J Nurs Sci. 2015;12(4):320-329. http://dx.doi.org/10.1111/ jjns. 12071. 